\title{
Neodymium-YAG laser iridotomy in angle closure glaucoma: preliminary study
}

\author{
N NAVEH, L ZBOROWSKY-GUTMAN, AND M BLUMENTHAL \\ From the Maurice and Gabriella Goldschleger Eye Institute, Sheba Medical Center, Tel-Hashomer, Sackler \\ School of Medicine, Tel-Aviv University, Tel-Aviv, Israel
}

SUMMARY A prospective short-term preliminary clinical study to evaluate the efficacy and immediate complications of Q-switched Nd-YAG laser iridotomy in the treatment of acute and chronic angle closure glaucoma is described. The follow-up period ranged from four to 10 months. Of 40 eyes treated $36(90 \%)$ required a single lasing session for patency (19, one application; 17 , two applications), and four eyes $(10 \%)$ required two sessions. Closure of the iridotomy site following Nd-YAG lasing due to pigment epithelium proliferation occurred in $10 \%$ of eyes, an incidence remarkably lower than that of argon laser iridotomy. Transitory closure or diminution of a prior patent iridotomy during the first hour after lasing was observed in $6.7 \%$ of eyes. Patency was again noted up to three weeks later and remained unchanged. Immediate postoperative complications included a marked increase in ocular pressure $(42 \%$ of eyes $)$, minimal transitory bleeding, and transitory localised corneal oedema at the lasing site. Persistent iridocorneal adhesion at the lasing site was noted in three eyes, and localised lenticular opacities, of nonprogressive type, were observed in one eye.

Argon laser iridotomy is at present ${ }^{1-7}$ the procedure of choice in the United States for the treatment of pupillary block glaucoma. However, despite modified argon laser techniques, difficulties in penetration of light blue and dark brown irides have been widely reported. ${ }^{\mathrm{x}-12}$

The Q-switched neodymium (Nd)-YAG laser causes tissue disruption by optical breakdown and resulting shockwave, making iris colour irrelevant. ${ }^{13}$ Initial reports on the efficacy of the Nd-YAG laser indicate important advantages in this method..$^{13-16}$ In the present study the ability of the Nd-YAG laser to produce iridotomy, and the complications associated with this procedure, are further investigated.

\section{Materials and methods}

Q-switched Nd-YAG laser iridotomy was performed in 32 patients (40 eyes), divided into three groups: 18 patients (24 eyes) with chronic angle closure glaucoma; six patients (eight eyes) with acute angle closure glaucoma; and eight patients (eight fellow

Correspondence to $\mathrm{N}$ Naveh, MD. Maurice and Gabriclla Goldschleger Eyc Institute. Sheba Medical Center, Tel-Hashomer. Tel-Aviv. Isracl. eyes) in whom acute angle closure glaucoma had occurred in the other eye some time in the past. Chronic angle closure glaucoma was diagnosed in those patients without a clear history of an acute attack who had narrow angle approaches and peripheral anterior synechiae (PAS) in at least one eye. Patients with secondary angle closure glaucoma were excluded from the study. The distribution of patients according to age, sex, and diagnosis is given in Table 1.

The patients were admitted to the series sequentially over a period of three months and were aware of the investigative nature of the therapy. The follow-up period ranged from four to 10 months. Six patients (eight eyes) in whom previous argon laser procedures had failed were included.

Prior to laser therapy all patients underwent ophthalmic examination, including Snellen visual acuity testing and Goldmann applanation tonometry. Pilocarpine hydrochloride $2 \%$ was administered 30 minutes before surgery.

The laser procedure was performed on an outpatient basis with topical anaesthesia (proparacaine $0.5 \%$ ). The Fankhauser Q-switched Nd-YAG laser (LASAG, Thun, Switzerland) was used in all cases, 
Table 1 Distribution of patients according to age, sex, and diagnosis

\begin{tabular}{|c|c|c|c|c|c|c|}
\hline \multirow[t]{2}{*}{ Diagnosis } & \multirow{2}{*}{$\begin{array}{l}\text { No. of } \\
\text { patients }\end{array}$} & \multicolumn{3}{|c|}{ Age (years) } & \multicolumn{2}{|c|}{ Sex } \\
\hline & & $\begin{array}{l}55- \\
65\end{array}$ & $\begin{array}{l}66- \\
75\end{array}$ & 75 & $F$ & $M$ \\
\hline $\begin{array}{l}\text { Chronic angle closure } \\
\text { glaucoma }\end{array}$ & $18(24)^{*}$ & 5 & 10 & 3 & 10 & 8 \\
\hline $\begin{array}{l}\text { Acute angle closure } \\
\text { glaucoma }\end{array}$ & $6(8)$ & 2 & 3 & 1 & 4 & 2 \\
\hline $\begin{array}{l}\text { Fcllow cyes to cyes with } \\
\text { prior acute angle closure } \\
\text { glaucoma }\end{array}$ & $8(8)$ & 3 & 5 & & 4 & 4 \\
\hline Total & $32(40)$ & 10 & 18 & 4 & 18 & 14 \\
\hline
\end{tabular}

${ }^{*}$ Figure in brackets indicates number of eyes involved.

and a Russel-Fankhauser iris lens was placed on the eye. The Fankhauser method for power settings consisted of a burst of 2 to 4 pulses, with selected energy levels varying from 6 to $10 \mathrm{~mJ}$ in the multimode train. Iridotomy was located, preferably basally, at an iris crypt in the superior nasal or temporal quadrant.

Successful penetration was manifested intraoperatively either by a gush of aqueous humour containing pigment epithelium particles from the posterior chamber, or by visibility of the anterior lens capsule. If the first burst failed to create a patent iridotomy, a second burst was fired during the same session, aimed at a different site.

The treated eyes were observed for iridotomy patency, changes in ocular pressure, and bleeding for the first five postoperative minutes. The presence of inflammation and debris in the anterior chamber, lens changes, gonioscopic appearance, and synechial formation were noted at hourly intervals for the next four hours. Patients returned for follow-up at one day, one week, and two weeks after treatment and at monthly intervals thereafter.

Topical steroids, four times daily, were started on the day of laser treatment and continued until the end of the first postoperative week. Preoperative glaucoma medications were continued as necessary. In cases in which ocular pressure increased to more than $10 \mathrm{mmHg}$ over baseline during the first four postoperative hours, oral glycerine $3 \mathrm{ml} / \mathrm{kg}$ body weight was given. Patients in this group were followed up at 90-minute intervals until ocular pressure returned to normal.

\section{Results}

Penetration was achieved during one session with either one or two laser applications in 36 eyes $(90 \%)$; a second session was required for four eyes $(10 \%)$ (Table 2). Of the 36 eyes in which a patent iridotomy was achieved during one laser session 19 needed only a single laser application, and 17 required a second application.

The total energy necessary to produce iridotomy ranged from 20.8 to $97.0 \mathrm{~mJ}$ (mean, $62.3 \pm 12.4 \mathrm{~mJ}$ ), with bursts at mean levels of $9 \cdot 6 \pm 2 \cdot 1$ mJ with 2 to 4 pulses. The mean total energy levels used for the second application were considerably higher than those used with the first $(42 \cdot 1 \pm 11 \cdot 8$ and $26 \cdot 2 \pm 3 \cdot 4$ $\mathrm{mJ}$, respectively; $\mathrm{p}=0 \cdot 001$ ) (Table 2 ).

In four eyes the iridotomy closed within six weeks after treatment. In two dark brown eyes and one light blue eye closure was due to proliferation of pigment epithelium. In the fourth eye the initial opening was slit-like and closed two weeks after treatment without clear evidence of pigment epithelium proliferation. In all four cases a repeat laser session proved effective in reopening the iridotomy site.

During laser application most patients complained of a severe discomfort, causing many to jerk their head back suddenly. In most cases the pain subsided shortly after treatment. The iridotomy site was typically elongated, with ragged edges, and was sometimes surrounded by iridoschisis-like areas.

All patients showed an immediate severe response in the anterior chamber, consisting mostly of pigmented debris of +2 to +3 .

In six eyes an unusual sequence of events was noted. During laser treatment an opening was clearly obtained, but soon thereafter the opening narrowed dramatically, so that endotomy patency was questionable or negative. In two of these cases the

Table 2 Energy requirements for Nd-YAG laseriridotomy

\begin{tabular}{|c|c|c|c|c|c|c|c|}
\hline \multirow{2}{*}{$\begin{array}{l}\text { No. of laser } \\
\text { sessions }\end{array}$} & \multirow{2}{*}{$\begin{array}{l}\text { No. of } \\
\text { applications }\end{array}$} & \multirow{2}{*}{$\begin{array}{l}\text { Total energy } \\
(m J): \text { mean }(S D)\end{array}$} & \multicolumn{2}{|c|}{ No. of eyes } & \multicolumn{3}{|c|}{ Diagnosis } \\
\hline & & & Blue & Brown & $C A C G$ & $A A C G$ & Felloweye \\
\hline Onc session & 1 application & $30 \cdot 5(6 \cdot 1)$ & 10 & 9 & 12 & 4 & 5 \\
\hline One session & $\begin{array}{l}\text { 1st application } \\
\text { 2nd application }\end{array}$ & $\begin{array}{l}26 \cdot 2(34 \cdot 0) \\
42 \cdot 1(11 \cdot 3)\end{array}$ & 11 & 6 & 9 & 3 & 3 \\
\hline Two sessions & $\begin{array}{l}\text { 1st session } \\
\text { 2nd session }\end{array}$ & $\begin{array}{l}48 \cdot 0(14 \cdot 0) \\
85 \cdot 0(12 \cdot 0)\end{array}$ & 2 & 2 & 2 & 1 & 1 \\
\hline
\end{tabular}

$\mathrm{CACG}=$ chronic angle closure glaucoma. $\mathrm{AACG}=$ acute angle closure glaucoma. 
Table 3 Postoperative complications of Nd-YAG laser iridotomy

\begin{tabular}{|c|c|c|c|c|}
\hline \multirow{2}{*}{\multicolumn{2}{|c|}{ Complications }} & \multirow{2}{*}{$\begin{array}{l}\text { No. of } \\
\text { eyes }\end{array}$} & \multicolumn{2}{|c|}{ Iris colour } \\
\hline & & & Brown & Blue \\
\hline \multirow[t]{2}{*}{ Ocular pressure increase* } & $10 \mathrm{mmHg}$ & 17 & 5 & 12 \\
\hline & $10 \mathrm{mmHg}$ & 9 & 6 & 3 \\
\hline \multirow[t]{2}{*}{ Blecding } & 'Strcaky' & 7 & 5 & 2 \\
\hline & hyphacma 5\% & 1 & 1 & - \\
\hline \multirow[t]{2}{*}{ Localised corncal oedema } & Transitory & 3 & - & 3 \\
\hline & Persistent & 1 & 1 & - \\
\hline Iridocorncal adhesion & & 3 & 1 & 2 \\
\hline Focal lenticular opacities & & 1 & 1 & 一 \\
\hline
\end{tabular}

${ }^{*}$ Difference between IOP one hour after iridotomy and preoperative (baseline) value.

progressive rapid closing of the iridotomy was actually observed while the treatment lens was still on the eye. In the remaining four cases diminution of the iridotomy was noticed at the 60-minute follow-up period. However, in each of these eyes widening of the iridotomy eventually occurred, as the iridotomy was patent at the two-week follow-up examination and remained unchanged during the entire follow-up period of more than three months.

The immediate postoperative complications are shown in Table 3 . Seventeen eyes $(42 \%)$ showed an increase in ocular pressure of more than $10 \mathrm{mmHg}$ over baseline (the mean ocular increase was 23.0 (SD 5) $\mathrm{mmHg}$ ); these included 12 eyes $(28 \%)$ with increases of more than $18 \mathrm{mmHg}$ over baseline. This increase in ocular pressure did not correlate with the preoperative ocular pressure, the degree of ocular inflammation, the energy requirements for iridotomy, or the amount of iris bleeding. However, 12 of the 17 eyes $(71 \%)$ with an immediate increase in pressure postoperatively had blue irides, whereas the percentage of blue irides of all eyes involved in the study was $58 \%$ (Table 2 ).

Minimal bleeding from iris vessels which lasted up to three minutes occurred in eight eyes $(20 \%)$. Only one eye showed formation of a $5 \%$ hyphaema, which cleared the following day (Table 3 ).

In three eyes localised corneal oedema with Descemet folds corresponding to the area of laser application was noted a few hours after lasing and lasted up to four days. This transitory corneal damage occurred in eyes in which Nd-YAG iridotomy was performed soon after resolution of an attack of angle closure glaucoma, while the eyes were still inflamed and with the anterior chamber unusually narrow.

Iridoschisis-like changes surrounding the iridotomy opening were observed in many of the patients; however, persistent adhesion of the schitic iris stroma to the cornea was noted in only three patients at the two-week follow-up visit. Persistent localised corneal opacity with Descemet break overlying the laser treated site was observed in one patient (Table 3).

Focal lenticular opacity without rupture or break of the anterior lens capsule occurred in one case, and some pigment deposition on the lens overlying the iridotomy site was observed in another (Table 3).

\section{Discussion}

Q-switched Nd-YAG laser iridotomy in humans has so far been studied for a short time in a limited number of eyes, achieving penetration in all cases with only minor and transient complications. ${ }^{1.2-15}$ In our series patent iridotomies were created after a single lasing session in 36 of the 40 glaucomatous eyes studied $(90 \%)$ and after two sessions in the remaining four eyes $(10 \%)$. In previous studies on Nd-YAG laser iridotomy a patent iridotomy was created in one treatment session in every case. ${ }^{13-1.5}$ Robin and Pollack ${ }^{15}$ used both the American Medical Optics YAG-1000 and the Coherent-JK prototype Nd-YAG lasers, whereas Fankhauser ${ }^{14}$ and $\mathrm{Klapper}^{13}$ used a Nd-YAG laser similar to the one used herein.

The total energy levels used in our work in eyes successfully penetrated within one session were compatible with those used by Fankhauser ${ }^{14}$ and Klapper. ${ }^{13}$ However, in the present study bursts of 6 to $10 \mathrm{~mJ}$ of 2 to 4 pulses each were applied in the multimode train; Fankhauser ${ }^{14}$ and Klapper ${ }^{13}$ applied bursts of 4 to $8 \mathrm{~mJ}$ of 4 pulses each in the fundamental mode. The failure to penetrate the iris within one session in $10 \%$ of eyes in the present study might be partly due to these differences in technique, though other factors may also have been involved (this being our initial experience with the Nd-YAG laser). Interestingly, of the four eyes that required two NdYAG lasing sessions to achieve penetration two dark brown eyes of one patient had undergone argon laser iridotomy twice prior to Nd-YAG laser iridotomy with negative results.

Closure of the iridotomy site following Nd-YAG lasing due to pigment epithelium proliferation occurred in four of the eyes $(10 \%)$ included in this study - three darkly pigmented irides and one light blue iris. Two of the darkly pigmented eyes belonged to the same patient with a history of repeated closure of argon laser iridotomy prior to iridotomy by $\mathrm{Nd}$ YAG laser.

Ours are the first reported cases of pigment epithelium proliferation resulting in iridotomy closure following Nd-YAG lasing in patients with angle closure glaucoma. (The only cases of Nd-YAG endotomy closure thus far have been reported by Klapper ${ }^{13}$ in patients with neovascular glaucoma and uveitis.) The incidence of closure of Nd-YAG laser 
iridotomy as shown in our series is still remarkably lower than that of argon laser iridotomy, which requires reopening in one-third of cases. ${ }^{346}$ This difference has been attributed to the differing effects of argon thermal energy and Nd-YAG shockwave on pigment epithelium cell disruption. ${ }^{16}$ However, full evaluation of the incidence of Nd-YAG iridotomy closure requires larger and longer-term studies.

Immediate postoperative closure or diminution of a prior open endotomy to the degree that patency became questionable was observed in $6.7 \%$ of eyes. However, in each of the eyes involved the closure or diminution was transitory, as patency was observed up to three weeks following lasing, and iridotomy size remained unchanged thereafter throughout the entire follow-up period of more than three months. The mechanism of the immediate transitory closure or diminution of the endotomy following Nd-YAG lasing has not yet been described and may involve stromal disruption by shockwave. Continuous progressive widening of $\mathrm{Nd}-\mathrm{YAG}$ iridotomy at later stages has been observed in animals but has not yet been seen in humans, ${ }^{16}$ while widening of argon laser iridotomy during the follow-up period in humans is widely accepted and was recently documented. ${ }^{17}$

The immediate postoperative complications were characterised by a marked increase in ocular pressure within the first two postoperative hours, noted in $42 \%$ of eyes included in our series. In $28 \%$ of eyes the pressure remained elevated by more than $10 \mathrm{mmHg}$ over baseline despite hyperosmotic treatment during the first 4 to 6 hours. There was no correlation between the increase in ocular pressure and the energy levels used, the degree of anterior chamber inflammation, or the presence of iris bleeding. Robin and Pollack ${ }^{15}$ found that in $65 \%$ of eyes treated with Nd-YAG laser iridotomy there was some increase in ocular pressure (range 1 to $38 \mathrm{mmHg}$ ) during the first three postoperative hours, with only two patients requiring treatment with glycerine. In the series of Fankhauser ${ }^{14}$ and Klapper ${ }^{13}$ a rise in ocular pressure occurred in only 2 of 20 eyes treated. This low incidence of ocular pressure increase after lasing, as compared with ours, might be due to the differences in technique but requires further evaluation, as total energy levels did not differ in these studies.

In our series iris bleeding, evident in $20 \%$ of eyes, was minimal and was absorbed rapidly after onset. This finding is in good agreement with previous data showing frequent bleeding following Nd-YAG laser iridotomy in humans. ${ }^{15}$

In our series corneal lesions following Nd-YAG laser iridotomy occurred in five eyes $(12.5 \%)$. These included three eyes with transitory corneal oedema above the application site and one eye with nonprogressive corneal opacity at the lasing site. Three of the eyes with corneal lesions were characterised by narrow chambers a few. days after resolution of an acute attack of pupillary block. The number of corneal lesions following pulsed lasing is inversely proportional to the distance of optical breakdown. ${ }^{11} 19$

Iridoschisis-like changes surrounding the laser site, as well as ragged endotomy edges (unlike the sharp edges found following argon iridotomy), were observed in many patients and were uneventful. However, in three eyes with exceedingly narrow chambers and an iridotomy located peripherally persistent iridocorneal adhesion at the endotomy site was noted at the two-week follow-up visit. These are the first reported cases of iridoschisis-like changes at the laser site, and it is our impression that they are not due to inaccurate focusing and are hardly surprising from the explosive nature of iris photodisruption.

Lenticular opacities observed in our series were of a non-progressive nature. Lenticular damage following Nd-YAG iridotomy might be attributed to the extension of the laser explosion to a distance of 450 $\mu \mathrm{m}$ from the lasing site, as shown recently. ${ }^{19}$

\section{References}

1 Abraham RK, Miller GL. Outpatient argon laser iridectomy for angle closure glaucoma. A two-year study. Ophthalmology (Rochester) 1975; 79: 529-38.

2 Podos SM, Kels B, Moss A, et al. Continuous wave argon laser iridectomy in angle closure glaucoma. Am J Ophthalmol 1979; 88: 836-42.

3 Quigley HA. Long term follow up of laser iridotomy. Ophthalmology (Rochester) 1981; 88: 218-24.

4 Pollack IP. Use of argon laser energy to produce iridotomics. Ophthalmic Surg 1980; 11: 506-15.

5 Robin AL, Pollack IP. Argon laser peripheral iridotomies in the treatment of primary angle closure glaucoma-long term follow up. Arch Ophthalmol 1982; 100: 919-23.

6 Schwartz L, Rodrigues M, Spaeth G, et al. Argon laser iridotomy in the treatment of patients with primary angle closure or pupillary block glaucoma. A clinicopathologic study. Ophthalmology (Rochester) 1978; 85: 294-309.

7 Harrad RA, Stannard KP, Shilling JS. Argon laser iridotomy. $\mathrm{Br}$ J Ophthalmol 1985; 69: 368-72.

8 Minning CA. The use of green only argon laser for iridotomy in blue eyed patients. Am J Ophthalmol 1983; 96: 114-5.

9 Naveh-Floman N, Blumenthal M. A modificd technique for serial use of argon and neodymium: YAG lasers in laser iridotomy. Am J Ophthalmol 1985; 100: 485-6.

10 Ritch R. Argon laser treatment for medically unresponsive angle closure. Am J Ophthalmol 1982; 94: 197.

11 Ritch R, Palmberg P. Argon laser iridectomy in densely pigmented irides. Am J Ophthalmol 1982; 93: 800-1.

12 Stctz D, Smith H, Ritch R. A simplificd technique for laser iridectomy in blue irides. Am J Ophthalmol 1983; 96: 249-51.

13 Klapper R. Q-switched neodymium: YAG laser iridotomy. Ophthalmology (Rochester) 1984; 91: 1017-21.

14 Fankhauser F. The Q-switched laser. Principles and clinical results. In: Trokel SL, ed. YAG laser ophthalmic microsurgery. Norwalk, Connecticut: Appleton-Century-Crofts, 1983.

15 Robin AL, Pollack IP. A comparison of ncodymium: YAG and argon laser iridotomies. Ophthalmology (Rochester) 1984; 91: $1011-6$. 
16 Van der Zypen E. Fankhauser F. Bebie H. Marshall J. Changes of the ultrastructure of the iris after irradiation with intense light: study of long-term effects after irradiation with argon ion, ND:YAG and Q-switched ruby lasers. Adv Ophthalmol 1979; 39: $59-180$.

17 Sachs SW. Schwartz B. Enlargement of laser iridotomies over time. Br J Ophthalmol 1984: 68: 570-3.
18 Kerr Muir MG, Sheppard ES. Drainage to the corneal endothelium during $\mathrm{Nd} / \mathrm{YAG}$ photodisruption. Br J Ophthalmol 1985; 69: 77-81.

19 Khodadoust AA, Arkfeld DF, Capriolli J. Ocular effects of ND:YAG laser. Am J Ophthalmol 1984; 98: 144-9.

Accepted for publication 25 June 1986. 